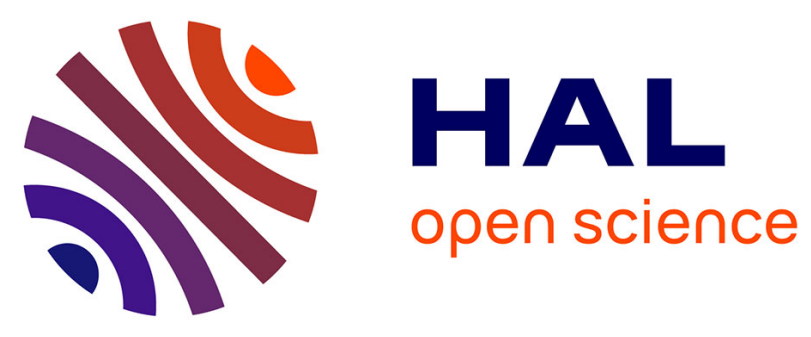

\title{
Slant strained band development during flat to slant crack transition in AA 2198 T8 sheet: in situ 3D measurements
}

\author{
Ante Buljac, Thibault Taillandier-Thomas, Thilo F. Morgeneyer, Lukas \\ Helfen, Stéphane Roux, François Hild
}

\section{To cite this version:}

Ante Buljac, Thibault Taillandier-Thomas, Thilo F. Morgeneyer, Lukas Helfen, Stéphane Roux, et al.. Slant strained band development during flat to slant crack transition in AA 2198 T8 sheet: in situ 3D measurements. International Journal of Fracture, 2016, 200 (1-2), pp.49-62. 10.1007/s10704015-0052-z . hal-01385406

\section{HAL Id: hal-01385406 \\ https://hal.science/hal-01385406}

Submitted on 21 Oct 2016

HAL is a multi-disciplinary open access archive for the deposit and dissemination of scientific research documents, whether they are published or not. The documents may come from teaching and research institutions in France or abroad, or from public or private research centers.
L'archive ouverte pluridisciplinaire HAL, est destinée au dépôt et à la diffusion de documents scientifiques de niveau recherche, publiés ou non, émanant des établissements d'enseignement et de recherche français ou étrangers, des laboratoires publics ou privés.

\section{()ㅜ(1)}

Distributed under a Creative Commons Attribution - NonCommercial| 4.0 International 


\title{
Slant strained band development during flat to slant crack transition in AA 2198 T8 sheet: in situ 3D measurements
}

\author{
Ante Buljac • Thibault Taillandier-Thomas • \\ Thilo F. Morgeneyer • Lukas Helfen . \\ Stéphane Roux • François Hild
}

Received: October 21, 2015/ Accepted: ?

\begin{abstract}
In this work 3D strain and damage analyses are performed in the immediate vicinity of the notch root of a flat CT-like specimen made of aluminum alloy. Experimental data, partially exploited by Morgeneyer et al (2014b), were obtained by using synchrotron laminography and the 3D reconstructed volumes are subsequently analyzed via Digital Volume Correlation. These data enable for in situ assessments of strain fields and ductile damage in the zone where the stress triaxiality evolves from elevated to lower levels, which is accompanied by flat-to-slant crack transition. The measured strain field patterns in this area are analyzed herein in a systematic manner by studying the incremental strain activity during several loading steps. It is shown that from the very beginning of the loading history multiple slant strained bands appear in front of the notch root while the corresponding damage growth sets in at later loading stages and higher strains. The activity of the different strained bands at the notch root is alternating between different locations over the loading history. However, the band leading to final rupture is always active. The region where slant fracture occurs is identified to be in plane strain condition with respect to the crack propagation direction.
\end{abstract}

Keywords Damage · Digital Volume Correlation · Flat-to-slant transition . Laminography $\cdot$ Plasticity

A. Buljac, T. Taillandier-Thomas, F. Hild, S. Roux Laboratoire de Mécanique et Technologie (LMT)

ENS Cachan/CNRS/Université Paris-Saclay

61 avenue du Président Wilson, 94235 Cachan, France

E-mail: buljac@lmt.ens-cachan.fr

A. Buljac, T. Taillandier-Thomas, T.F. Morgeneyer

MINES ParisTech, PSL Research University, MAT-Centre des matériaux, CNRS UMR 7633, BP 8791003 Evry, France

L. Helfen

ANKA/Institute for Photon Science and Synchrotron Radiation

Karlsruhe Institute of Technology (KIT), D-76131 Karlsruhe, Germany

L. Helfen

European Synchrotron Radiation Facility (ESRF), F-38043 Grenoble, France 


\section{Introduction}

One of the objectives of engineering design processes is to enhance the prediction of failure and to improve the fracture resistance of engineering materials. This is achieved through extensive studies on the material behavior and the implementation of new production technologies. As a consequence, the majority of structural alloys nowadays fails by ductile fracture characterized by three principal stages, namely, nucleation, growth and coalescence of voids. Unlike classical global fracture mechanics, micromechanicsbased approaches describe these three stages with more physical insight. Still, a general model does not yet exist to predict failure.

While at higher stress triaxiality levels available material and numerical models keep the pace at increasing accuracy in predictions of ductile failure mode and critical strains (Gurson 1977. Tvergaard and Needleman 1984 Lemaitre 1992), lower stress triaxiality levels still present serious challenges (Faleskog and Barsoum, 2013 Papasidero et al 2014). Ductile damage micromechanisms responsible for crack initiation and propagation in such conditions are still not fully understood. In particular, the link between stress triaxiality, Lode parameter and strain to fracture remains an open question. Even a clear definition on how to measure strain to fracture is not established at present (Papasidero et al 2014).

The example that summarizes the main difficulties experienced while modeling and simulating ductile fracture is the flat-to-slant transition. The ductile crack propagation path in sheet-like samples usually consists of a flat part (i.e., normal to the loading direction) with a characteristic triangular shape due to tunneling, which is followed by a slant surface (Mahgoub et al, 2003 Lan et al 2006, Morgeneyer et al 2011. Besson et al 2013). Such sudden change of crack growth from mode I to a combination of modes I and III may reduce the material toughness compared with the same samples broken under pure mode I loading. During ductile tearing of alloy sheets the crack can also undergo so-called flip-flopping (ElNaaman and Nielsen, 2013). A slant crack has numerically been shown to dissipate less energy during the tearing process than a flat crack (Besson et al 2013). The propagating crack is in plane strain conditions with respect to the crack propagation direction (Bron and Besson, 2006). Although considerable efforts have been made, numerical simulations of the flat-to-slant transition by using continuum mechanics without prescribing the crack path remain very challenging. The underlying physics of this failure process remain unclear.

Such strain localization phenomena in metals have been studied theoretically by Needleman and Tvergaard (1992), who found that localization is favored by material behaviors that form a sharp vertex on the yield surface, by material damage and by heating due to plastic deformation, leading to thermal softening at high strain rates. Recently, the influence of strain rate on localization has also been identified (Needleman 2015).

To experimentally assess damage processes in the material bulk, tomography techniques have successfully been used in the past to study failure in structural engineering materials such as Al-alloys (Maire and Withers 2014), steels (Lorthios et al 2010 Landron et al 2012) and polymers even achieving nanometer resolutions (Morgeneyer et al 2014a). However, geometrical conditions for sheet material tests cannot readily be met via tomography as only axisymmetric or stick-shape-like specimens can be tested in situ. Only stopped cracks could be cut-out and assessed in 3D by tomography at micrometer resolution. This limitation is overcome by resorting to synchrotron radiation 
computed laminography (Helfen et al 2005, 2009: Altapova et al 2012) that provides the opportunity to assess in situ damage processes in laterally extended sheet-like specimens using physical boundary conditions of engineering relevance and associated naturally developing plastic zone sizes of the order of several millimeters (Morgeneyer et al 2011, Helfen et al, 2012. Shen et al 2013). As such, it complements tomographic analyses. For example, it has been shown that pre-existing pores elongate and rotate toward the slant crack during flat to slant crack transition (Ueda et al 2014).

Experimentally, Morgeneyer et al (2014b) reported early slant strained bands $1 \mathrm{~mm}$ ahead of the notch root of a CT-like specimen without any significant damage development in a recrystallized $\mathrm{Al}-\mathrm{Cu}-\mathrm{Li}$ alloy by using synchrotron laminography Helfen \begin{tabular}{l|l|l|l|l|l|}
\hline et al & 2005 & 2011 & $2012)$
\end{tabular} and Digital Volume Correlation with a global formulation (Roux et al 2008). Despite the strong competition with other classes of structural materials such as polymer based composites, new generations of metallic alloys (e.g., Al-Cu-Li) are used for future transport applications as they display great potential for application of new joining techniques (Le Jolu et al. 20142015 ).

The present paper considers the same experimental acquisitions (Morgeneyer et al 2014b for a different Region of Interest (ROI), which is very close to the notch root, and also encompassing part of the ROI analyzed in the previous study. Such an approach should enable for the observation of strain and damage interactions in the flat-toslant transition region at micrometer resolution. The underlying question arises: does damage onset or does strain localization occur first when getting closer to the notch root? What is the difference in strain fields between the flat and the slant crack? The paper, which aims to answer these questions, is structured as follows. The imaging and mechanical experimental setup, and material properties are first introduced. The basic principles of DVC together with strain uncertainty assessments and definition of the ROI are outlined next. The results are finally discussed. The focus is on incremental strain activity in the zone ahead of the notch root.

\section{Material and experimental setup}

The material of the CT-like specimen studied herein (i.e., AA 2198) is in its recrystallized state and after an artificial aging treatment (T8). It is produced by Constellium $\mathrm{C}-\mathrm{Tech}$ and represents the latest generation of Al-Cu-Li alloys. Due to its low density, enhanced mechanical properties and corrosion resistance AA 2198 is widely used in high demanding branches such as the commercial aircraft industry. The composition (in wt\%) of the aluminum alloy is $2.9-3.5 \mathrm{Cu}, 0.8-1.1 \mathrm{Li}, 0.25-0.8 \mathrm{Mg}, 0.1-0.5 \mathrm{Ag}$, 0.04-0.18 Zr, balance Al. The yield strength is $\sim 440 \mathrm{MPa}$ and the ultimate tensile strength is $\sim 500 \mathrm{MPa}$. Therefore the heat treatment endows the material a low work hardening. The intermetallic particle volume fraction is found to be $\sim 0.3-0.4 \%$ while the initial porosity is very low (i.e., $<0.03$ vol\%). The very low volume fraction of secondary phases makes this material very challenging for Digital Volume Correlation (DVC) since it relies on natural markers.

The material processing directions are the rolling direction $(\mathrm{L})$, the transverse direction $(\mathrm{T})$ and the short-transverse direction in the through thickness $(\mathrm{S})$. In the present experiment the loading is applied in the T-direction and the L-direction corresponds to that of crack propagation. More details on the material properties can be found in (Chen 2011, Morgeneyer et al, 2014b). 
The studied sample is imaged by synchrotron radiation computed laminography, which is a $3 \mathrm{D}$ non-destructive experimental technique used for scanning laterally extended sheet-like objects (Helfen et al, 2006 Maurel et al. 2012 Bull et al. 2013 Reischig et al 2013). Unlike synchrotron radiation computed tomography limited to stick-like samples, laminography enables for conducting a whole range of tests using more realistic (i.e., engineering-relevant) boundary conditions. The CT-like specimen, with dimensions $1 \times 60 \times 70 \mathrm{~mm}$, is prepared by using EDM to produce a notch root of radius $r=0.17 \mathrm{~mm}$. The remaining ligament is $24 \mathrm{~mm}$ wide. The testing device (Figure 1.a)) applies the load by controlling the notch opening displacement (NOD) while the specimen is placed in a specially prepared frame (not shown here) including two anti-buckling plates that avoid out-of-plane motions (Morgeneyer et al, 2011 2013).

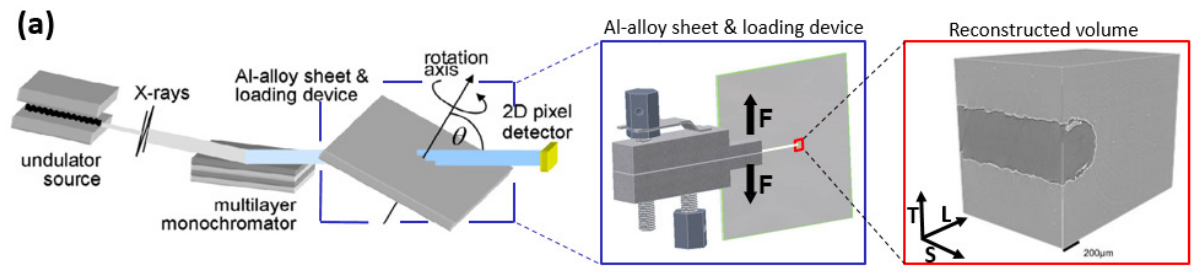

(b)

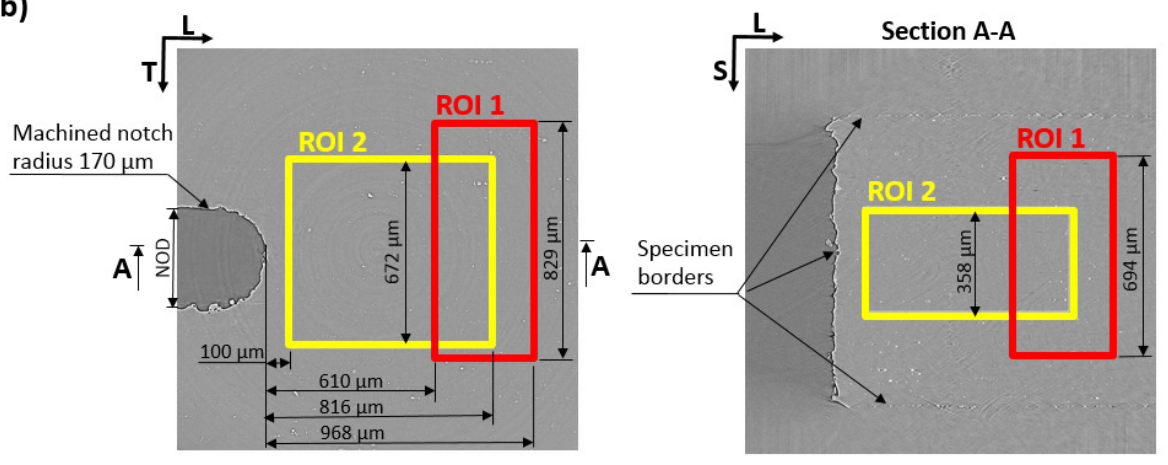

Fig. 1 (a) Shematic view of the laminography experimental setup with scanned region in front of the notch root (red) and reconstructed volume. (b) Reconstructed volume sections with ROI positions and relevant dimensions for DVC analyses. ROI 1 corresponds to the analysis reported in (Morgeneyer et al 2014b) and ROI 2 is analyzed in this work

After applying each loading step (or NOD step), a scan is acquired while the sample is rotated about the laminographic axis (i.e., parallel to the specimen thickness direction $\mathrm{S}$ ). This axis is inclined with respect to the $\mathrm{X}$-ray beam direction by an angle $\theta \approx 65^{\circ}$ (Figure 1 (a)). A series of 1500 radiographs are then used to reconstruct 3D volumes by using a filtered-backprojection algorithm (Myagotin et al 2013). The reconstructed volumes represent the scanned region with a size of $2040 \times 2040 \times 2040$ voxels. The physical size (length) of 1 cubic voxel is equal to $0.7 \mu \mathrm{m}$. Conducting DVC analyses with the full size reconstructed volumes is computationally too demanding, therefore only a part of the reconstructed volume called Region of Interest is considered herein (i.e., ROI 2 shown in Figure 1 (b)). 


\section{Digital Volume Correlation}

\subsection{Principle}

DVC used herein is an extension of 2D global Digital Image Correlation (Besnard et al. 2006 Hild and Roux 2012). Each voxel inside the reconstructed volume contains the gray level information determined by the material ability to absorb X-rays. The reconstructed volume is represented by a discrete scalar field of the spatial coordinate $\boldsymbol{x}$. In the present case, the image contrast is mainly due to heavy intermetallic particles of micrometer size. The principle of DVC consists of matching the gray levels $f$ in the reference configuration $\boldsymbol{x}$ and those of the deformed volume $g$

$$
f(\boldsymbol{x})=g[\boldsymbol{x}+\boldsymbol{u}(\boldsymbol{x})]
$$

where $\boldsymbol{u}$ is the displacement field with respect to the reference volume. However, in real problems the strict conservation of gray level is not satisfied, especially in CL where deviations appear not just due to acquisition noise but also due to reconstruction artifacts because of missing information (angles) (Xu et al 2012). Consequently, the solution consists of minimizing the gray level residual $\rho(\boldsymbol{x})=f(\boldsymbol{x})-g[\boldsymbol{x}+\boldsymbol{u}(\boldsymbol{x})]$ by considering its L2-norm with respect to kinematic unknowns associated with the parameterization of the displacement field. Since a global approach is used in this work, the whole region of interest (ROI) is considered, the global residual $\Phi_{c}$

$$
\Phi_{c}^{2}=\sum_{R O I} \rho^{2}(\boldsymbol{x})
$$

is minimized with respect to the unknown degrees of freedom $u_{p}$ when the displacement is written as

$$
\boldsymbol{u}(\boldsymbol{x})=\sum_{p} u_{p} \boldsymbol{\Psi}_{p}(\boldsymbol{x})
$$

where $\boldsymbol{\Psi}_{p}(\boldsymbol{x})$ are the chosen displacement fields for the parameterization of $\boldsymbol{u}(\boldsymbol{x})$. Among a whole range of available fields, finite element shape functions are particularly attractive because of the link they provide between the measurement of the displacement field and numerical models. Thus, a weak formulation based on C8 finite elements with trilinear shape functions is chosen (Roux et al 2008).

\subsection{Strain resolution}

The DVC resolution is evaluated by correlating two scans of the unloaded sample with a small rigid motion applied between the acquisitions. Due to the noise contribution and reconstruction artifacts, these two volumes are not identical. Therefore, the measured displacement field accounts for the cumulated effects of laminography and DVC on the measurement uncertainty. From the mean gradient of the displacement field over each C8 element the Green Lagrange strain tensor and subsequently its second invariant will be used in the sequel as Von Mises' equivalent strain

$$
\epsilon_{e q}=\sqrt{\frac{2}{3} \epsilon_{d}: \epsilon_{d}}
$$

where $\epsilon_{d}$ denotes the deviator of the strain tensor $\boldsymbol{\epsilon}$. 
The uncertainty values are evaluated by the standard deviation of the measured displacement and calculated strain fields. Figure 2 shows the standard resolution levels for different $\mathrm{C} 8$ element sizes $\ell$ expressed in voxels. The results are virtually identical for both studied ROIs. Decreasing the element size is followed by an increase of the strain uncertainty. Keeping the same spatial resolution, the strain uncertainty can be further decreased by employing additional mechanical regularization procedures acting like low-pass displacement filters (Leclerc et al, 2011 Taillandier-Thomas et al, 2014). This type of regularization is not used herein. The element size used in this work is $\ell=16$ voxels (length) for all three directions, which yields a standard equivalent strain resolution of $0.3 \%$. This value represents the limit below which the estimated strain levels are not trustworthy.

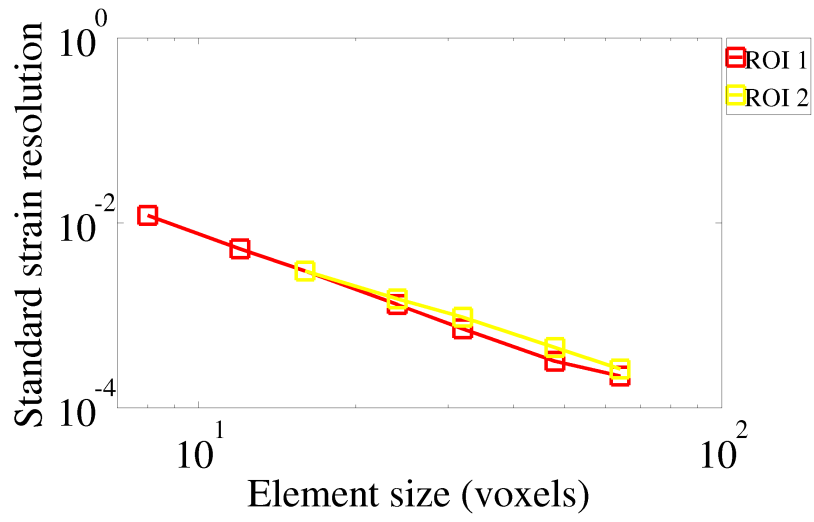

Fig. 2 Standard resolution of von Mises equivalent strain as a function of the element size expressed in voxels for a rigid-body-motion case. Two ROIs are considered in the DVC analyses (see Figure 1 $(\mathrm{b})$ )

\subsection{ROI positions}

The results from the previously studied ROI $1(\sim 800 \mu \mathrm{m}$ from the notch root, see Figure 1(b)) display from the first loading step on the formation of slant bands with strain levels at least one order of magnitude greater than the strain resolution (Morgeneyer et al 2014b). Furthermore, it is shown that at the same loading steps damage did not nucleate. Only at the very ultimate loading steps damage develops. The final crack path follows the strained band. The slant band and the corresponding crack path lead to the following question: what happens closer to the notch root?

For this purpose, a second ROI denoted as ROI 2 positioned in the vicinity of the notch root is extracted from the reconstructed volume (Figure 1 (b)). The two ROIs overlap thereby providing a common ground in both ROIs comparing the results. ROI 2 with dimensions $960 \times 1024 \times 512$ voxels is now extended in the L-direction reaching the notch root. Consequently the size in the S-dimension had to be decreased to be able to run the DVC measurements. Since close to the notch root the crack propagated earlier, all the calculations obtained for ROI 1 could not be performed for ROI 2. Therefore, 
only the converged solutions available for both ROIs will be discussed in the following. After conducting calculations and analyzing them, reliable results (i.e., before the crack has propagated through ROI 2) for both ROIs are obtained for incremental analyses of loading steps between states (0)-(1), (1)-(2) and (2)-(3).

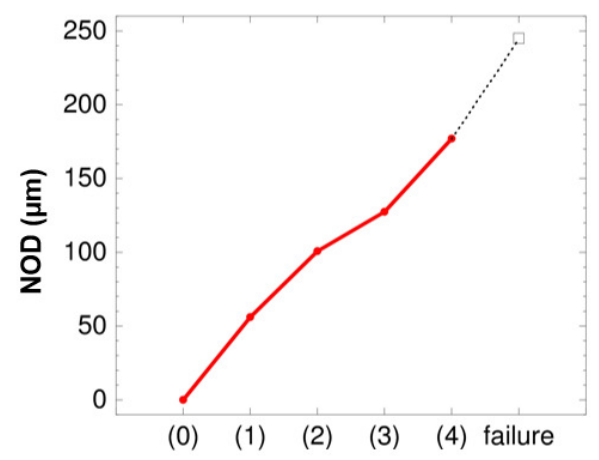

Fig. 3 Notch opening displacement (NOD) for the studied loading steps

As mentioned before, there is an overlapping zone between ROI 1 and ROI 2 (Figure 1 (b)). In Figure 4 the incremental equivalent strain maps are shown for the overlapping region for $\mathrm{T}$ and S-sections for the loading step (1)-(2). The color bar is limited to a maximum value of 0.08 to emphasize more the levels in the overlapping zone. The strain field is evaluated voxel-wise by using the shape functions associated with the C8 discretization. The equivalent strain difference is evaluated inside the overlapping region and the corresponding standard deviations are respectively equal to 0.0046 for load step (0)-(1), 0.0044 for load step (1)-(2) and 0.0040 for load step(2)-(3)). Since the standard strain resolution is equal to 0.003 , and the two strain evaluations are obtained for two different ROIs, it is expected that the two quantities are independent. Consequently, the standard deviation of the strain difference is expected to be equal to $\sqrt{2} \times 0.003=0.0042$, which is very close to the observed levels (mean value: 0.0043 ). This result fully validates the fact that the two results obtained on ROI 1 and ROI 2 can be merged into a single field.

\section{Results}

Incremental loading steps are especially interesting in terms of plastic activity. There are two different ways of displaying these results. First the fields are shown on the reference configuration of each analysis. Second, all results can be expressed in a Lagrangian way by reprojecting back all the measured incremental fields. However, some data are not available since the ROI 2 in the deformed configuration is significantly larger than ROI 2 in the reference configuration. In the sequel, the first approach will be used since it does not induce any loss of information, but special care has to be exercised to identify common features to make the comparison objective.

All the results reported hereafter have required the DVC analyses to converge, namely, the root mean square (RMS) displacement difference between two iterations is less than $10^{-4}$ voxel. An additional check is related to the residuals $\rho$. Figure 5 
(a)

(b)

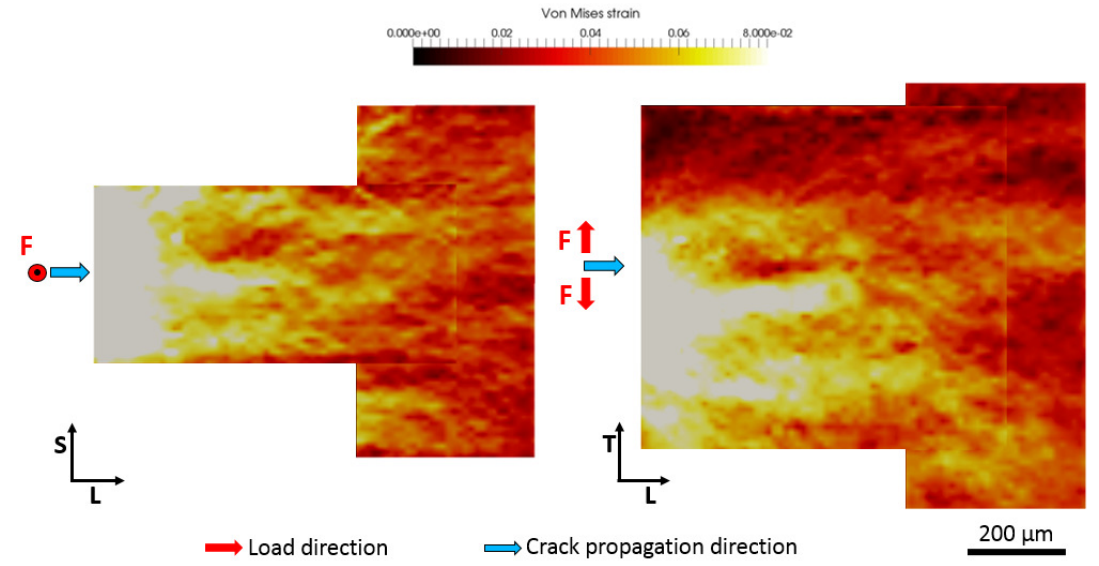

Fig. $4 \mathrm{~T}(\mathrm{a})$ and $\mathrm{S}(\mathrm{b})$ middle sections displaying incremental equivalent strain maps for both ROI 1 and ROI 2 for loading step (1)-(2)

shows one L-section of ROI 2 in the reference configuration $f$ of the three analyses. The incremental equivalent strain fields display very complex patterns that will be commented in the following. This explains why special care was exercised to make sure that these results are trustworthy. Consequently, sections of the deformed volumes corrected by the measured displacement $g[\boldsymbol{x}+\boldsymbol{u}(\boldsymbol{x})]$ and the corresponding residual maps $\rho$ are also shown. These last maps do not display areas with high residuals. This is an additional confirmation that, even though the registration is very difficult, the strain fields are deemed trustworthy.

Sections normal to L and S-axes (referred to as L and S-sections in the sequel) of incremental equivalent strain fields are respectively shown in Figures 6 and 7 L-sections will be displayed with shifts of 200 voxels starting from the location close to the notch root. For S-sections, the second column of displayed results corresponds to the sample mid-plane while the remaining two sections are located 50 voxels from the ROI 2 faces. The magnitude of the incremental strain fields close to the notch root are significantly higher than in the remainder of the ROI. To capture interesting features, the color bar scale is limited to a maximum level of 0.1 for all displayed sections. By moving away from the notch root, the incremental strain field that is initially concentrated in a horizontal zone evolves to a slant position by forming several inclined bands. In all cases the difference between strain levels inside and outside the bands are more than one order of magnitude higher than the reported strain uncertainties. Consequently, the reported results are deemed trustworthy.

Interestingly, $\sim 250 \mu \mathrm{m}$ away from the notch root slant bands are observed (Figure 6. while the initial notch radius is $\sim 170 \mu \mathrm{m}$. One should note that this is the case already from the first loading step (i.e., NOD $=50 \mu \mathrm{m}$ ) where incremental strain field heterogeneities are observed in front of the notch root (Figure6(a)). The slant strained pattern is composed of multiple bands, which is different from that reported farther away from the notch (Morgeneyer et al 2014b). In the region closer to the notch, series of " $\mathrm{X}$ " type bands form in the plane normal to the crack propagation direction L. From the loading step (0)-(1) on, one of the slant bands is more active and pronounced than 


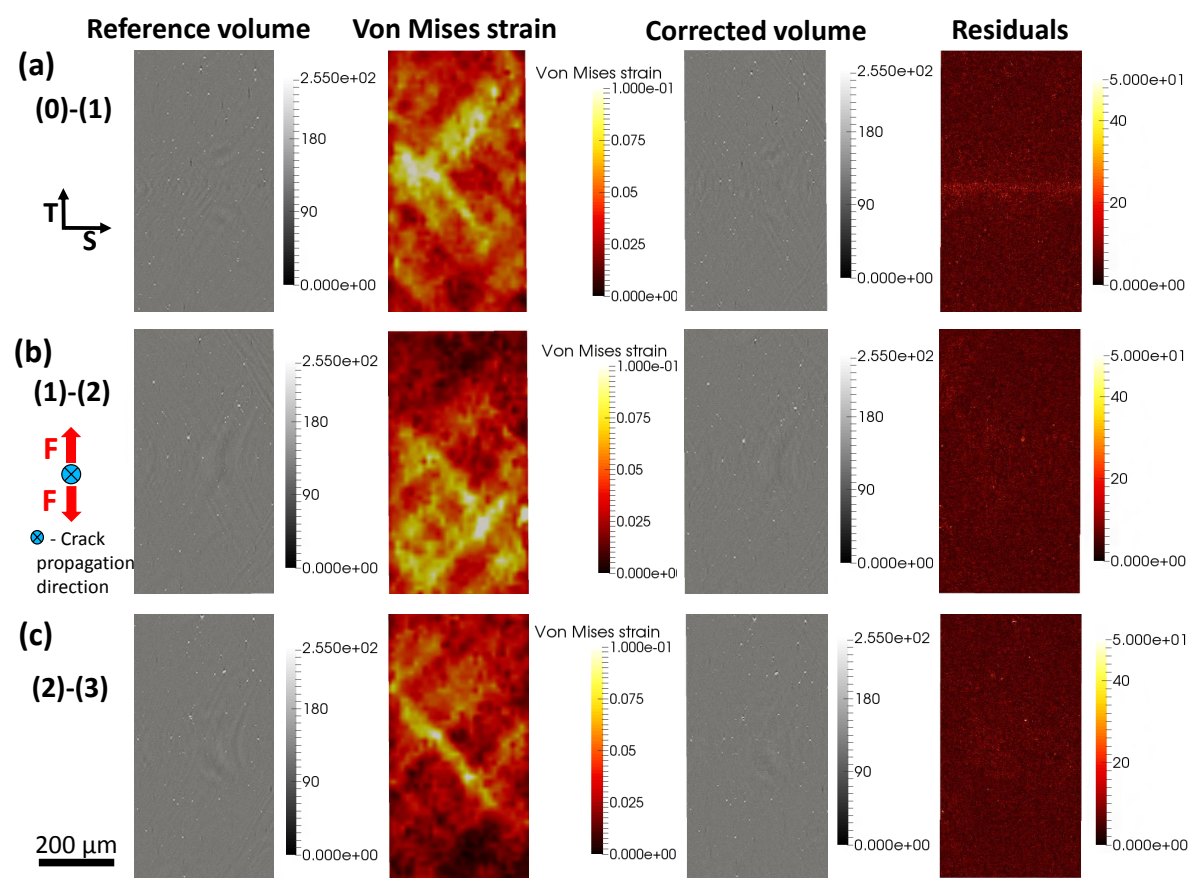

Fig. 5 L-sections $\sim 390 \mu \mathrm{m}$ away from the initial notch root. The first column corresponds to reconstructed laminography data in the reference configurations $f$, the second column shows incremental equivalent strain maps, the third column displays the deformed volume corrected by the measured displacement, and the fourth column the gray level residuals for loading steps (a): (0)-(1), (b): (1)-(2), (c) (2)-(3)

the other ones. For the load steps (1)-(2) (Figure 6(b)) and (2)-(3) (Figure 6(c)) the same observations are reported, namely, close to the notch the incremental strain field morphology is more complex, while farther away from the notch one X-shaped band remains with decreased strain levels.

Through the thickness, S-sections (Figure 7) reveal a complex incremental strain field shape, which is strongly localized near the notch root and later penetrates along the L-direction forming several regions of strain concentration that are aligned along the crack propagation direction. On the central plane three horizontal strained bands are active. For the first loading step, the upper and central one are active. In the following loading step (1)-(2) the central band remains active and a lower band becomes active. During loading step (2)-(3) the central and upper bands are again active. The existence of more than two bands and their alternating activity is a novel finding and not expected from von Mises plasticity.

The strain fields corresponding to the outer part of the ROI confirm that the strained bands are inclined in the L-section as they are not in the same location through the thickness. This pattern differs from the one that would be obtained via numerical simulations by using von Mises plasticity and isotropic hardening where typical plastic zone shapes around the notch can be seen (Morgeneyer et al. 2014b). First, one can hardly find such regular shapes with closed contours. Second, unlike numerical solu- 


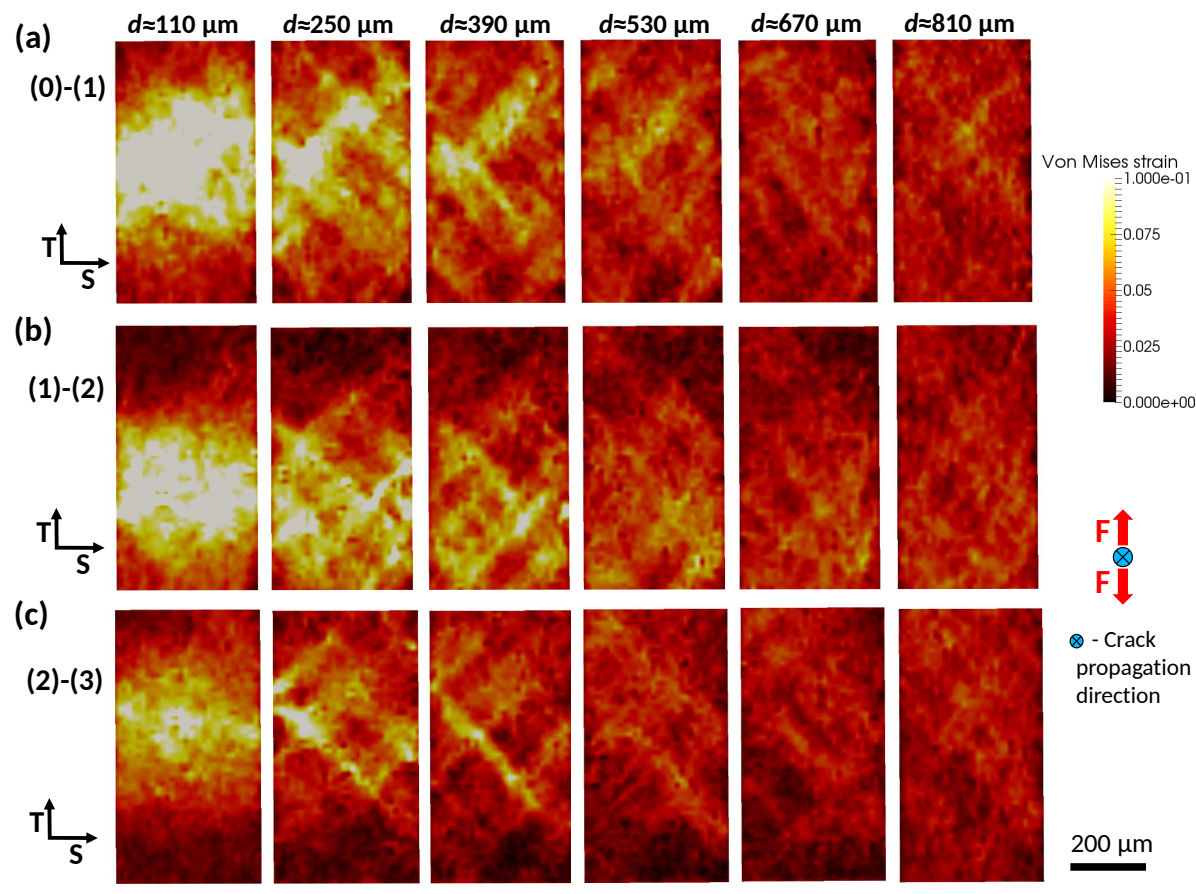

Fig. 6 Sections normal to the L-direction of incremental equivalent strain fields for loading step $(\mathrm{a}):(0)-(1),(\mathrm{b}):(1)-(2)$ and $(\mathrm{c}):(2)-(3) . d$ is distance from the initial notch root

tions, strong incremental strain field dependence with respect to the $\mathrm{S}$ axis is observed, therefore plane strain conditions in the thickness direction do not apply.

Figure 8 shows equivalent strain profiles along the line defined by the intersection of the L-section located $\approx 285 \mu \mathrm{m}$ from the notch root and the middle thickness plane of the specimen. After the onset of strain localization the other zones of the specimen that are not affected still remain active (i.e., the equivalent strain level still increases). Each additional loading step induces an accumulation of plastic strain but with significantly lower magnitudes.

In a previous work (Needleman and Rice, 1977) it has been shown that strain localization is easier under plane strain conditions. It is necessary to point out that plane strain conditions here refer to the T-S plane since strains in the crack propagation direction are close to zero. By means of laminography and DVC this can be checked. Figure 9 shows the incremental strain maps for the different strain components in the L-T plane for loading step (0)-(1). Despite the fact that the equivalent strain is high ( 0.07 to 0.1 or higher) over a large horizontal band, the strain in the crack propagation direction (L) is close to zero in most of the ROI. Only the area close to the notch undergoes necking (negative strains) in this direction. This is consistent with numerical simulations of crack initiation and propagation (Bron and Besson, 2006).

For more quantitative assessments of this phenomenon, Figure $10 \mathrm{~b}$ ) shows longitudinal strain profiles in the crack propagation direction plotted for the three different axes $\xi_{i}$ located in the mid-thickness plane of ROI 2 for loading step (2)-(3). This is representative, as the same trend has been found for all three loading steps (Figure 10 


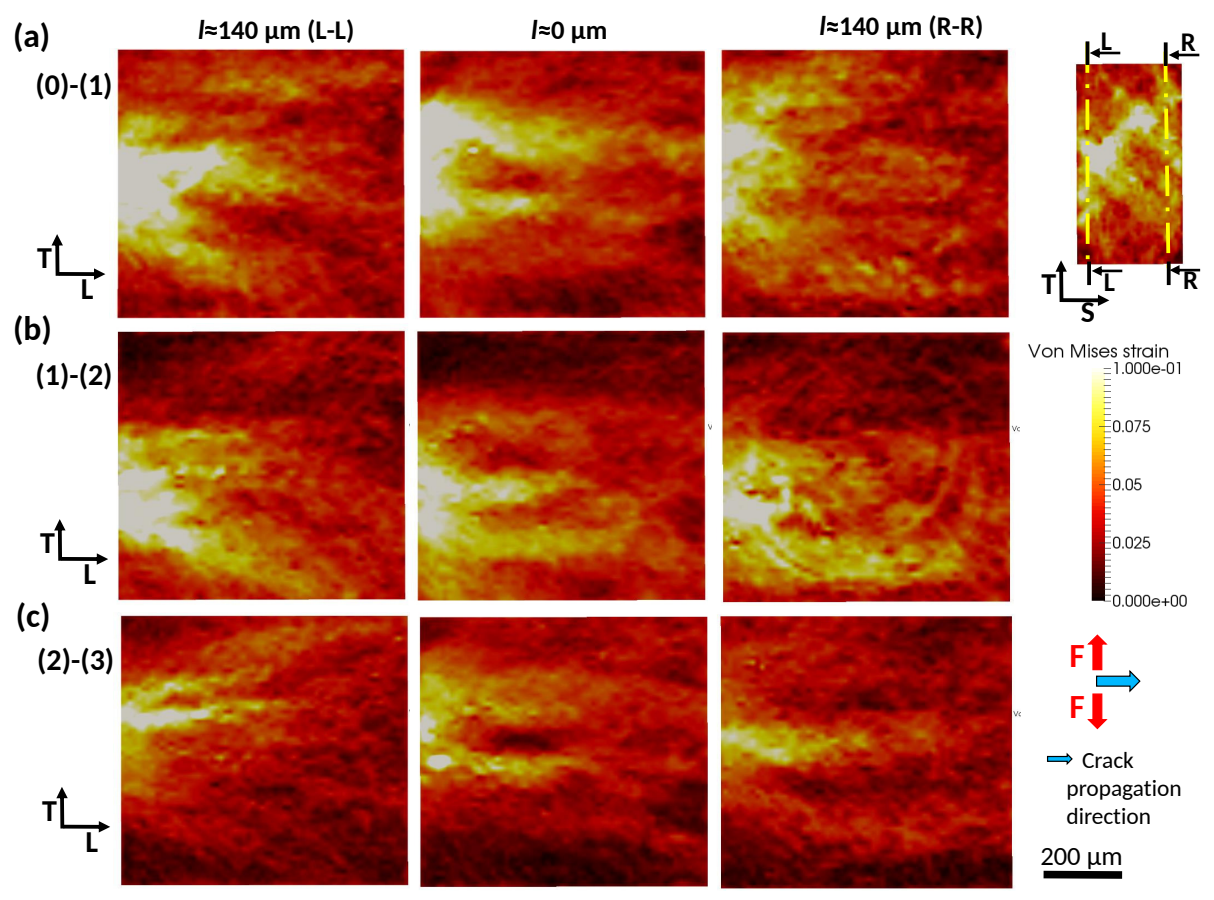

Fig. 7 Sections normal to S-direction of incremental equivalent strain fields for loading step $(\mathrm{a}):(0)-(1),(\mathrm{b}):(1)-(2)$ and $(\mathrm{c}):(2)-(3) . l$ is distance from the center line

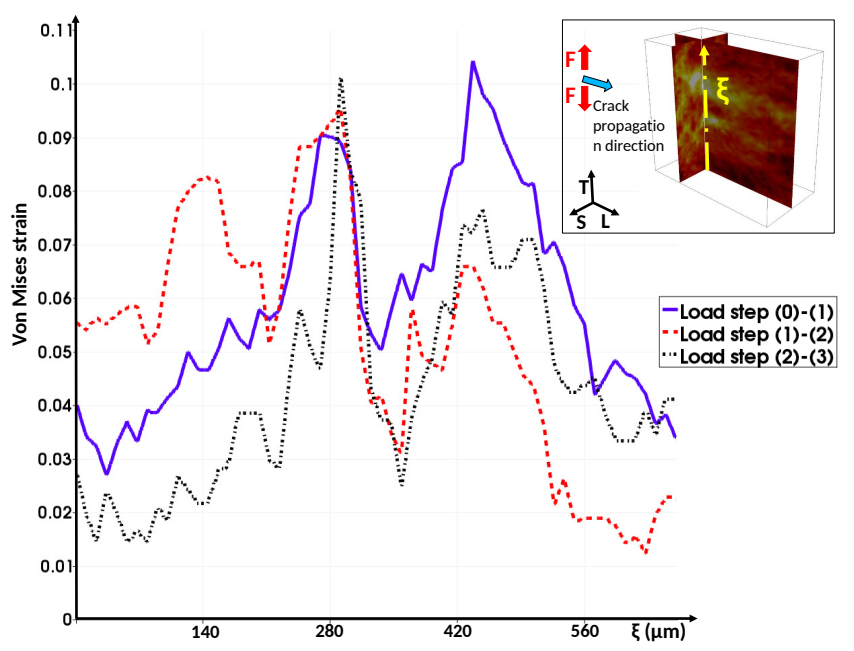

Fig. 8 Equivalent strain plotted along axis $\xi$ parallel to the T-direction $285 \mu \mathrm{m}$ from the notch root and on the mid-plane for loading steps (0)-(1), (1)-(2) and (2)-(3)

(a)). The LL strain profiles show negative levels $\sim-0.04$ close to the notch and up to about $300 \mu \mathrm{m}$ from the notch. LL-strain mean values close to zero are found farther away from the notch. Subsequent L-sections are reported for the equivalent strains 

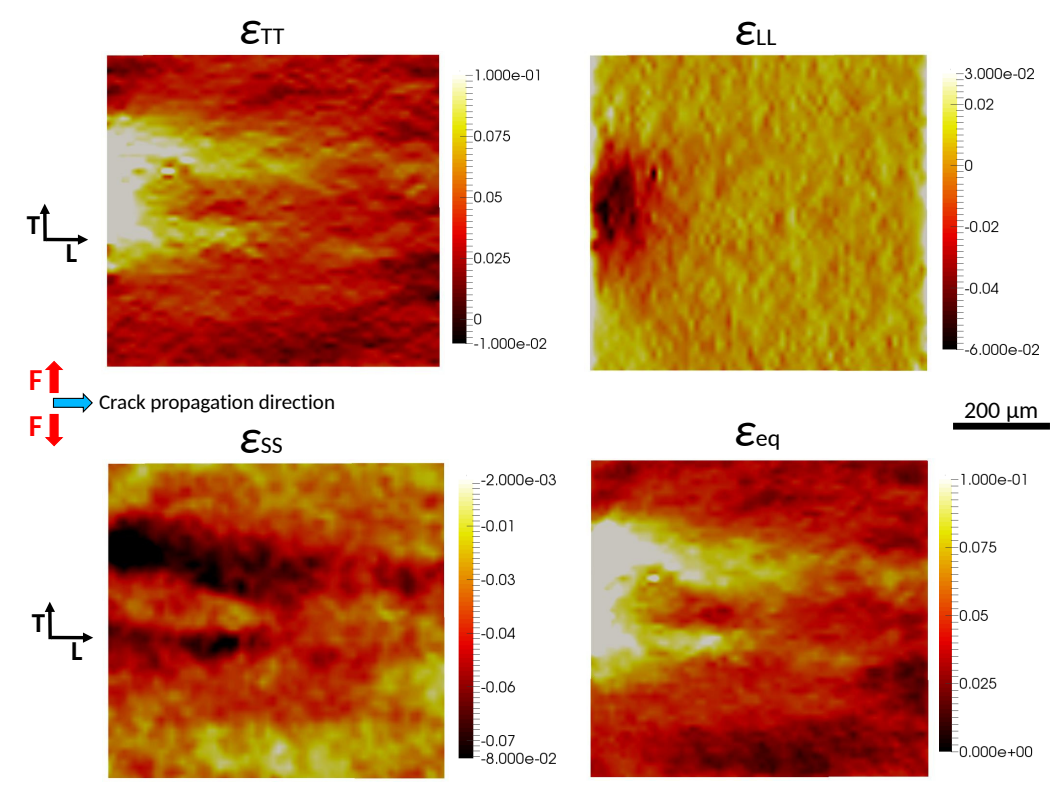

Fig. 9 Middle S-sections of normal strains in T, L and S-direction together with incremental equivalent strain field for the corresponding slice for loading step (0)-(1). The color bar has been limited to highlight strain concentration areas

for loading step (2)-(3) (Figure 10(b)). It can be seen that reaching the plane strain condition is accompanied with the existence of multiple slant strained bands.

Figure 11 shows 3D renderings of the segmented porosity/damage volumes and equivalent incremental strain fields. As expected from the previous analyses, strained bands are observed from the very beginning of the loading process. Conversely, void nucleation and growth is very limited, except for the loading step (2)-(3) where the damage activity is more developed mainly in the zone close to the notch root due to higher strains and stresses. Therefore, the observed slant bands are not induced by damage mechanisms. In comparison to the previously reported results (Morgeneyer et al, 2014b), it can be stated that even in the area closer to the notch root the same mechanisms prevail, namely, the onset and development of slant bands precedes damage, which points out that plasticity is the driving mechanism for the flat to slant transition. At later stages, very high strains develop within the bands and outside. These high levels of plasticity cause damage nucleation and growth leading to the final failure. This type of ductile failure corresponds to Mechanism 2 identified in Ref. (Tekoğlu et al 2015). However, compared with ROI 1, the strained bands in ROI 2 are more numerous and decrease in number when moving away from the notch root.

It is interesting to overlay the final crack path and equivalent incremental strain maps for three different positions along the L-direction for each loading step (Figure 12. Comparing both fields shows how far one can go in predicting the failure mode by observing early (incremental) strained bands. For loading step (2)-(3), the Lsection $\sim 250 \mu \mathrm{m}$ ahead of the initial notch root clearly reveals how the above reported complex incremental strain fields resulted in "zigzagged" failure patterns following the 


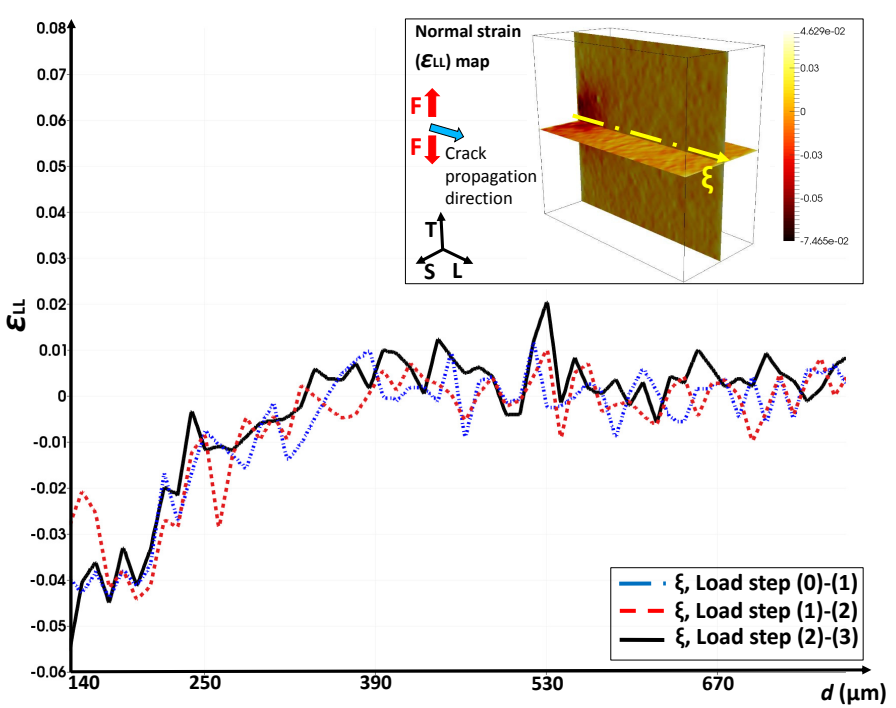

(a)

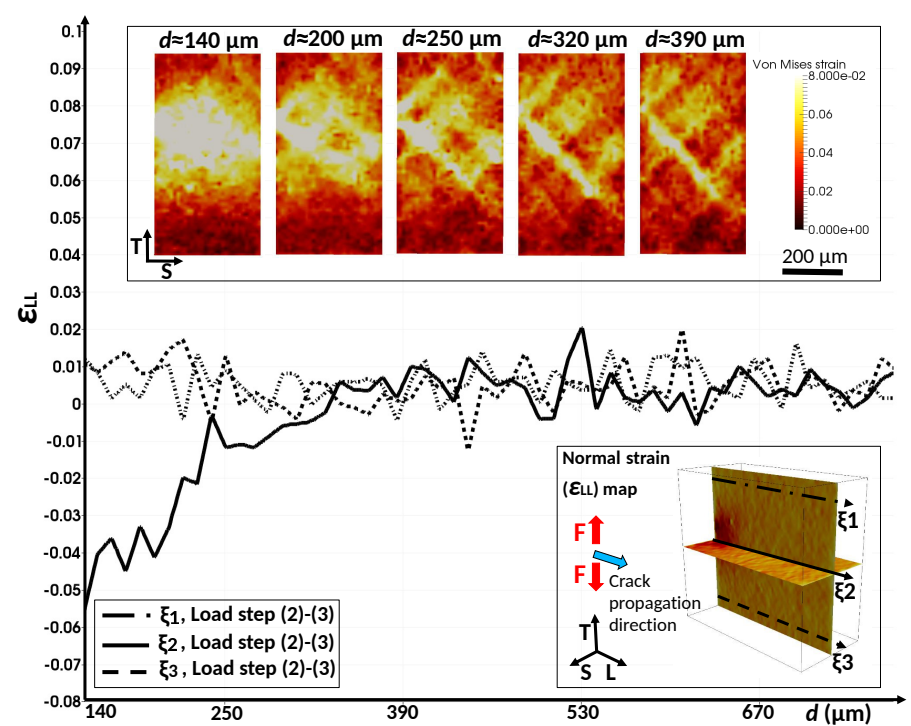

(b)

Fig. 10 (a) Strain profiles in the crack propagation direction (L) plotted along axis $\xi$ for loading steps (0)-(1), (1)-(2) and (2)-(3). (b) Strain profiles in the crack propagation direction for loading step (2)-(3) plotted along three different axes $\xi_{i}$ on the mid-plane. The L-sections of incremental equivalent strains are also shown. $d$ is distance from the initial notch root

strained band orientations. Close to the notch root there is a strong competition between different bands determining the future crack path. Although not simple, the 
a)

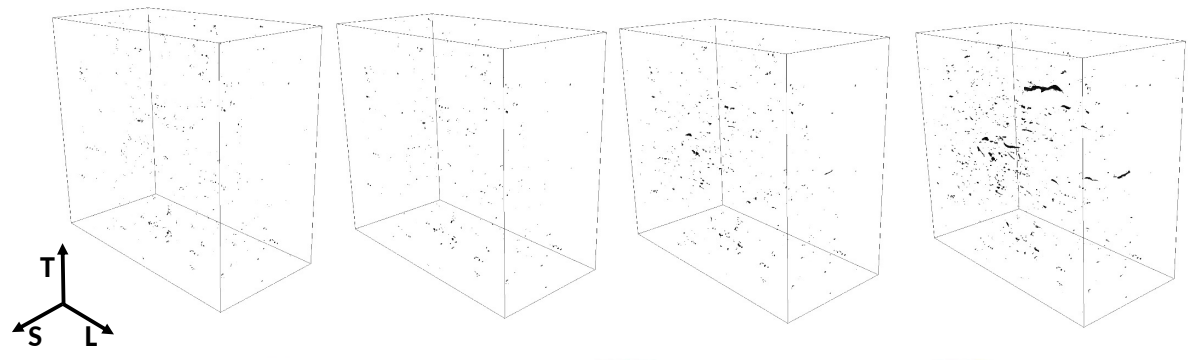

b)
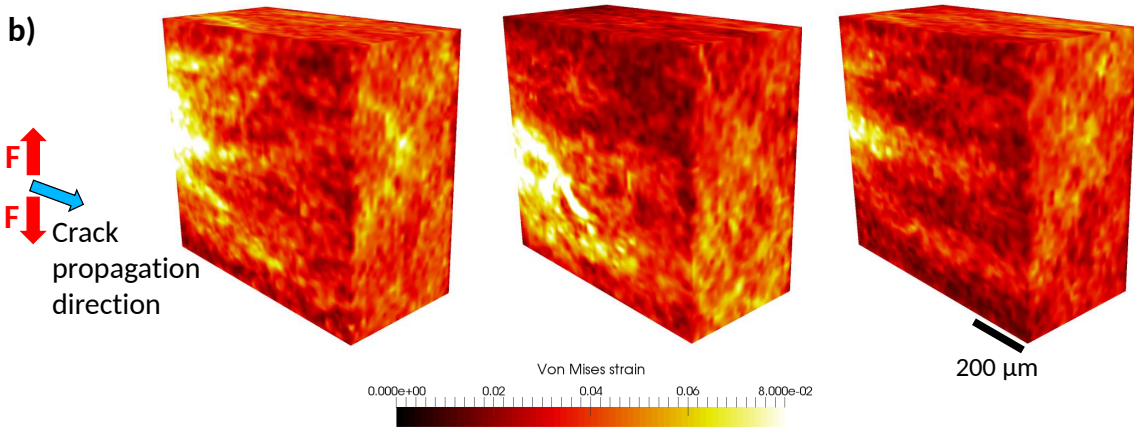

Fig. 11 (a) 3D rendering of void distribution for the undeformed (0) and deformed (1),(2),(3) volumes obtained by thresholding of gray levels. (b) Isometric view of incremental equivalent strain fields for loading steps (0)-(1), (1)-(2) and (2)-(3)

strained bands are regularly distributed, which determines the crack path to be either fully slanted or interrupted by $\sim 90^{\circ}$ changes in the propagation direction.

In the case of longer crack paths, such "zigzagged" patterns are also observed during flipping action where an already slant crack shifts to the opposite side (El-Naaman and Nielsen 2013). Regarding the previous observations, this zigzagged pattern can be considered as the result of small perturbations that favor deformation in another band while the previously active band is deactivated. It has been argued that this is most likely caused by a mechanical response as resistance to bending of the sample induced by slant crack propagation (El-Naaman and Nielsen 2013). What defines the preliminary 'choice' of the crack propagation direction is the asymmetry of the system as well as the loading conditions that favor one of already available strained bands, which ultimately determine the crack path. However, it is difficult to conclude on what causes those initial instabilities.

\section{Conclusions}

The plastic zone close to the notch of a CT-like specimen made of 2198-T8 aluminum alloy was studied in the material bulk by resorting to in situ laminography and Digital Volume Correlation. 3D incremental strain fields just in front of the notch root are measured to study the flat-to-slant transition in ductile failure of thin sheets. The understanding of such phenomena may help evaluate the material toughness. 

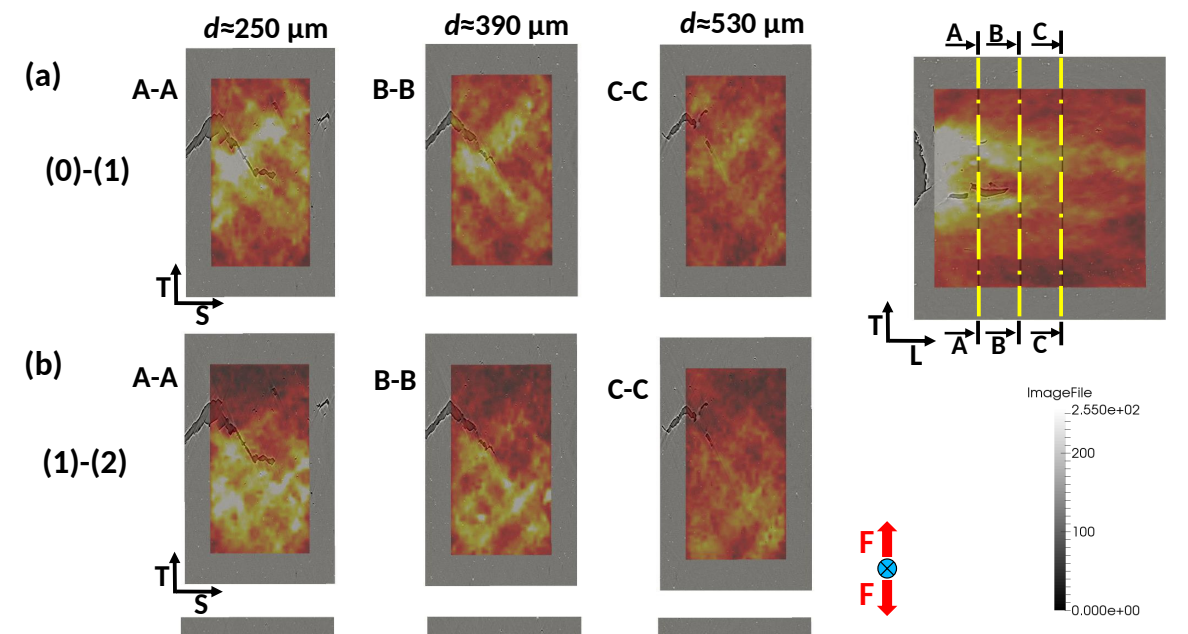

(c)
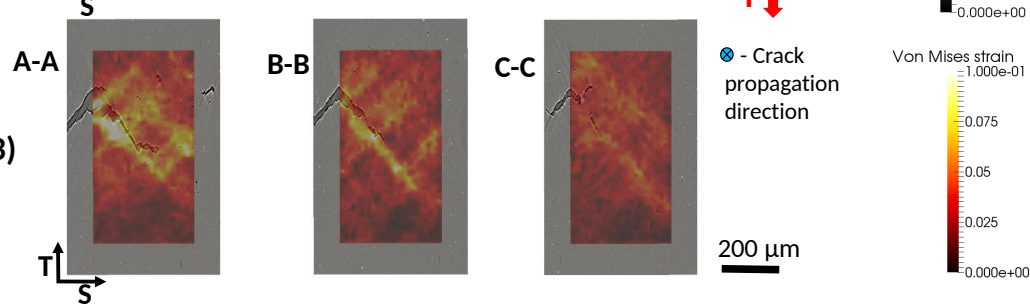

Fig. 12 Incremental equivalent strain fields printed over portion of reconstructed volumes showing the final crack path for loading steps (0)-(1) (a),(1)-(2) (b) and (2)-(3) (c). L-sections are located at a distance $d \sim 250 \mu \mathrm{m}, d \sim 390 \mu \mathrm{m}$ and $d \sim 530 \mu \mathrm{m}$ from the notch root

The consistency of the DVC results has been demonstrated by checking the correlation residual fields after convergence. No significant deviation has been observed from noise-related and reconstruction artifacts. Further, by analyzing overlapping zones between two studied Region of Interests (ROIs), namely, the first one from a previous work (Morgeneyer et al 2014b) and the second one analyzed herein the strain differences are very close to the measurement resolution.

It was shown that several slant strained bands form complex localized patterns when moving at a distance greater than $\sim 250 \mu \mathrm{m}$ from the notch root. Strained bands show alternating activity in this region by switching on and off during incremental loading steps. These incremental strain fields do not follow the conventional plastic zone in front of notched samples. The number of strained bands decreases with the distance to the notch. Normal strains in the crack propagation direction are confirmed to be close to zero. It was demonstrated that the onset of strained bands spatially coincide with reaching the plane strain state.

Furthermore, even in the close vicinity of the notch root, significant damage does not occur immediately after the onset of strained bands, which is believed to be the prevalent mechanism explaining the flat-to-slant transition in the studied aluminum alloy. Consequently, the final fracture path proceeds along the measured incremental strained bands. It can therefore be stated that early strained bands precede the crack path away from the notch root (Morgeneyer et al 2014b) and also getting very close to it for the reported experiment. 
Additional effort will be put on similar examinations of other materials of the same aluminum $2 \mathrm{xxx}$ series (e.g., materials with high work hardening, different microstructure, different heat treatments) to evaluate if the results obtained herein can be generalized to a greater variety of alloys.

Acknowledgements The financial support of the Fédération Francilienne de Mécanique and Agence Nationale de la Recherche (ANR-14-CE07-0034-02 grant for COMINSIDE project) is gratefully acknowledged. Constellium C-Tech supplied the material. We acknowledge the European Synchrotron Radiation Facility for provision of beamtime at beamline ID19 (experiment MA1006).

\section{References}

Altapova V, Helfen L, Myagotin A, Hänschke D, Moosmann J, Gunneweg J, Baumbach T (2012) Phase contrast laminography based on Talbot interferometry. Optics Express 20:6496-6508

Asserin-Lebert A, Besson J, Gourgues A (2005) Fracture of 6056 aluminum sheet materials: effect of specimen thickness and hardening behavior on strain localization and toughness. Mat Sci Eng A395(1-2):186-194

Besnard G, Hild F, Roux S (2006) "Finite-element" displacement fields analysis from digital images: Application to Portevin-Le Châtelier bands. Exp Mech 46:789-803

Besson J, McCowan C, Drexler E (2013) Modeling flat to slant fracture transition using the computational cell methodology. Eng Fract Mech 104:80-95

Bron F, Besson J (2006) Simulation of the ductile tearing for two grades of 2024 aluminum alloy thin sheets. Eng Fract Mech 73(11):1531-1552

Bron F, Besson J, Pineau A (2004) Ductile rupture in thin sheets of two grades of 2024 aluminum alloy. Mat Sci Eng A380(1-2):356-364

Bull DJ, Helfen L, Sinclair I, Spearing SM, Baumbach T (2013) A Synthesis of MultiScale 3D X-ray Tomographic Inspection Techniques for Assessing Carbon Fibre Composite Impact Damage. Compos Sci Technol 75:55-61

Chen J (2011) Ductile tearing of AA2198 aluminium-lithium sheets for aeronautic application. Phd thesis, thèse d'Université

El-Naaman S, Nielsen K (2013) Observations on mode I ductile tearing in sheet metals. Eur J Mech A/Solids 42:54-62

Faleskog J, Barsoum I (2013) Tension-torsion fracture experiments-part I: Experiments and a procedure to evaluate the equivalent plastic strain. Int J Solids Struct 50(2526):4241-4257

Gurson A (1977) Continuum Theory of Ductile Rupture by Void Nucleation and Growth: Part I - Yield Criterion and Flow Rules for Porous Ductile Media. ASME J Eng Mat Techn 99:2-15

Helfen L, Baumbach T, Mikulík P, Kiel D, Pernot P, Cloetens P, Baruchel J (2005) High-resolution three-dimensional imaging of flat objects by synchrotron-radiation computed laminography. Appl Phys Lett 86(7):071,915

Helfen L, Myagotin A, Pernot P, DiMichiel M, Mikulík P, Berthold A, Baumbach T (2006) Investigation of hybrid pixel detector arrays by synchrotron-radiation imaging. Nucl Inst Meth Phys Res B 563:163-166

Helfen L, Baumbach T, Cloetens P, Baruchel J (2009) Phase contrast and holographic computed laminography. Appl Phys Lett 94(104103) 
Helfen L, Myagotin A, Mikulík P, Pernot P, Voropaev A, Elyyan M, Di Michiel M, Baruchel J, Baumbach T (2011) On the implementation of computed laminography using synchrotron radiation. Rev Sci Instrum 82(063702)

Helfen L, Morgeneyer T, Xu F, Mavrogordato M, Sinclair I, Schillinger B, Baumbach $\mathrm{T}$ (2012) Synchrotron and neutron laminography for three-dimensional imaging of devices and flat material specimens. Int J Mat Res 2012(2):170-173

Hild F, Roux S (2012) Comparison of local and global approaches to digital image correlation. Exp Mech 52(9):1503-1519

Lan W, Deng X, Sutton MA, Chen C (2006) Study of slant fracture in ductile materials. Int J Fract 141:469-496

Landron C, Maire E, Adrien J, Suhonen H, Cloetens P, Bouaziz O (2012) Nondestructive 3-D reconstruction of the martensitic phase in a dual-phase steel using synchrotron holotomography. Scripta Materialia 66(12):1077-1080

Le Jolu T, Morgeneyer T, Denquin A, Sennour M, Laurent A, Besson J, GourguesLorenzon AF (2014) Microstructural Characterization of Internal Welding Defects and Their Effect on the Tensile Behavior of FSW Joints of AA2198 Al-Cu-Li Alloy. Met Mat Trans A45(12):5531-5544

Le Jolu T, Morgeneyer T, Denquin A, Gourgues-Lorenzon A (2015) Fatigue lifetime and tearing resistance of AA2198 Al-Cu-Li alloy friction stir welds: Effect of defects. Int J Fat 70:463-472

Leclerc H, Périé J, Roux S, Hild F (2011) Voxel-scale digital volume correlation. Exp Mech 51(4):479-490

Lemaitre J (1992) A Course on Damage Mechanics. Springer-Verlag, Berlin (Germany)

Lorthios J, Nguyen F, Gourgues AF, Morgeneyer T, Cugy P (2010) Damage observation in a high-manganese austenitic TWIP steel by synchrotron radiation computed tomography. Scripta Mat 63(12):1220-1223

Mahgoub E, Deng X, Sutton M (2003) Three dimensional stress and deformation fields around flat and slant cracks under remote mode I loading conditions. Eng Fract Mech $70: 2527-2542$

Maire E, Withers PJ (2014) Quantitative X-ray tomography. Int Mat Rev 59(1):1-43

Maurel V, Helfen L, N'Guyen F, Köster A, Di Michiel M, Baumbach T, Morgeneyer T (2012) Three-dimensional investigation of thermal barrier coatings by synchrotronradiation computed laminography. Scripta Mat 66:471-474

Morgeneyer T, Helfen L, Sinclair I, Proudhon H, Xu F, Baumbach T (2011) Ductile crack initiation and propagation assessed via in situ synchrotron radiation computed laminography. Scripta Mat 65:1010-1013

Morgeneyer T, Helfen L, Mubarak H, Hild F (2013) 3D Digital Volume Correlation of Synchrotron Radiation Laminography images of ductile crack initiation: An initial feasibility study. Exp Mech 53(4):543-556

Morgeneyer T, Proudhon H, Cloetens P, Ludwig W, Roirand Q, Laiarinandrasana L, Maire E (2014a) Nanovoid morphology and distribution in deformed HDPE studied by magnified synchrotron radiation holotomography. Polymer 55(25):6439-6443

Morgeneyer T, Taillandier-Thomas T, Helfen L, Baumbach T, Sinclair I, Roux S, Hild F (2014b) In situ 3D observation of early strain localisation during failure of thin Al alloy (2198) sheet. Acta Mat pp 78-91

Myagotin A, Voropaev A, Helfen L, Hänschke D, Baumbach T (2013) Efficient Volume Reconstruction for Parallel-Beam Computed Laminography by Filtered Backprojection on Multi-Core Clusters. IEEE Trans Image Process 22(12):5348-5361 
Needleman A (2015) The Effect of Rate Dependence on Localization of Deformation and Failure in Softening Solids. J Appl Mech 82(2):021,002-7

Needleman A, Rice J (1977) Limits to Ductility Set by Plastic Flow Localization. In: Koistinen D, Wang N (eds) General Motors Research Laboratories Symposium, Mechanics of Sheet Metal Forming, Plenum Press, pp 237-267

Needleman A, Tvergaard V (1992) Analyses of Plastic Flow Localization in Metals. Appl Mech Rev 45(3S):S3-S18

Papasidero J, Doquet V, Mohr D (2014) Determination of the Effect of Stress State on the Onset of Ductile Fracture Through Tension-Torsion Experiments. Exp Mech 54(2):137-151

Reischig P, Helfen L, Wallert A, Baumbach T, Dik J (2013) Non-invasive, threedimensional x-ray imaging of paint layers. Apply Phys A 111:983-995

Roux S, Hild F, Viot P, Bernard D (2008) Three dimensional image correlation from X-Ray computed tomography of solid foam. Comp Part A 39(8):1253-1265

Shen Y, Morgeneyer T, Garnier J, Allais L, Helfen L, Crépin J (2013) Threedimensional quantitative in situ study of crack initiation and propagation in AA6061 aluminum alloy sheets via synchrotron laminography and finite-element simulations. Acta Mat 61(7):2571-2582

Taillandier-Thomas T, Roux S, Morgeneyer T, Hild F (2014) Localized strain field measurement on laminography data with mechanical regularization. Nucl Inst Meth Phys Res B (324):70-79

Tekoğlu C, Hutchinson JW, Pardoen T (2015) On localization and void coalescence as a precursor to ductile fracture. Phil Trans Royal Soc London A: Mathematical, Physical and Engineering Sciences 373(2038)

Tvergaard V, Needleman A (1984) Analysis of the cup-cone fracture in a round tensile bar. Acta Metall 32(1):157-169

Ueda T, Helfen L, Morgeneyer T (2014) In situ laminography study of threedimensional individual void shape evolution at crack initiation and comparison with Gurson-Tvergaard-Needleman-type simulations. Acta Mat 78:254-270

Xu F, Helfen L, Baumbach T, Suhonen H (2012) Comparison of image quality in computed laminography and tomography. Optics Express 20:794-806 


\section{Additional Material}
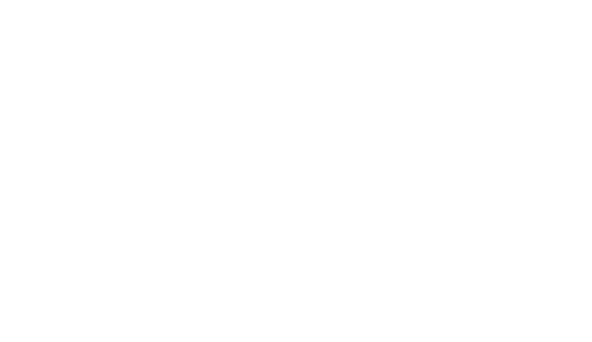

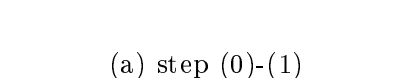
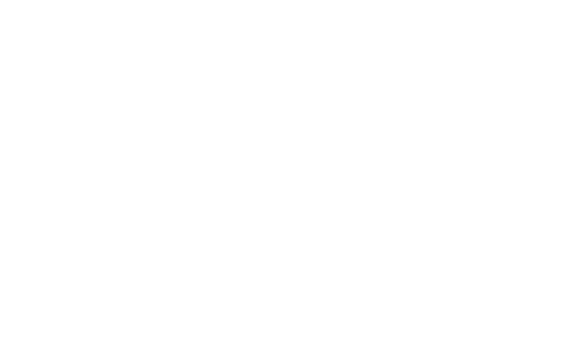

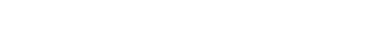

(b) step (1)-(2)
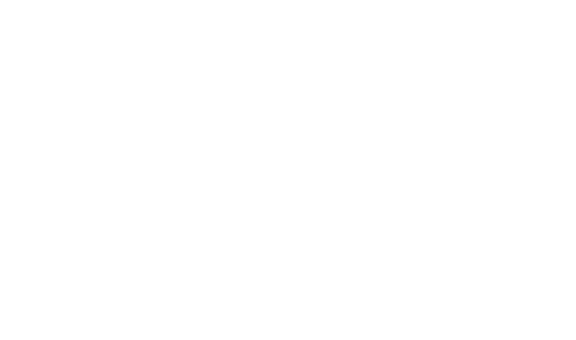

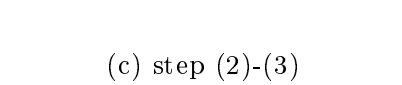

Fig. 13 Movies showing L-sections of incremental equivalent strain field for the three analyzed loading steps. The results of both ROI 1 and ROI 2 are shown 